This item was submitted to Loughborough's Research Repository by the author.

Items in Figshare are protected by copyright, with all rights reserved, unless otherwise indicated.

\title{
Investigation of the evolution of crystal size and shape during temperature cycling and in the presence of a polymeric additive using combined process analytical technologies
}

\section{PLEASE CITE THE PUBLISHED VERSION}

http://dx.doi.org/10.1021/acs.cgd.6b01683

\section{PUBLISHER}

American Chemical Society (ACS)

\section{VERSION}

VoR (Version of Record)

\section{PUBLISHER STATEMENT}

This work is made available according to the conditions of the Creative Commons Attribution 4.0 International (CC BY 4.0) licence. Full details of this licence are available at: http://creativecommons.org/licenses/by/4.0/

\section{LICENCE}

CC BY 4.0

\section{REPOSITORY RECORD}

Simone, Elena, Anneke R. Klapwijk, Chick C. Wilson, and Zoltan Nagy. 2017. "Investigation of the Evolution of Crystal Size and Shape During Temperature Cycling and in the Presence of a Polymeric Additive Using Combined Process Analytical Technologies". figshare. https://hdl.handle.net/2134/26035. 


\section{Investigation of the Evolution of Crystal Size and Shape during Temperature Cycling and in the Presence of a Polymeric Additive Using Combined Process Analytical Technologies}

Published as part of a Crystal Growth and Design virtual special issue of selected papers presented at the 12th International Workshop on the Crystal Growth of Organic Materials (CGOM12 Leeds, UK)

Elena Simone, ${ }^{\dagger, \S_{(0)}}$ Anneke R. Klapwijk, ${ }^{\ddagger}$ Chick C. Wilson," and Zoltan K. Nagy*, ${ }^{*, \S_{\odot}}$

${ }^{\dagger}$ School of Food Science and Nutrition, University of Leeds, Leeds, LS29JT, U.K.

${ }^{\S}$ Department of Chemical Engineering, Loughborough University, Loughborough LE113TU, U.K.

${ }^{\ddagger}$ EPSRC Centre for Innovative Manufacturing in Continuous Manufacturing and Crystallisation (CMAC) at the University of Bath, Bath BA2 7AY, U.K.

"Department of Chemistry, University of Bath, Bath BA2 7AY, U.K.

${ }^{\perp}$ School of Chemical Engineering, Purdue University, West Lafayette, Indiana 47907-2100, United States

Supporting Information

ABSTRACT: Crystal size and shape can be manipulated to enhance the qualities of the final product. In this work the steady-state shape and size of succinic acid crystals, with and without a polymeric additive (Pluronic P123) at $350 \mathrm{~mL}$, scale is reported. The effect of the amplitude of cycles as well as the heating/cooling rates is described, and convergent cycling (direct nucleation control) is compared to static cycling. The results show that the shape of succinic acid crystals changes from plate- to diamond-like after multiple cycling steps, and that the time required for this morphology change to occur is strongly related to the type of cycling. Addition of the polymer is shown to affect both the final shape of the crystals and the time needed to reach size and shape steady-state conditions. It is shown how this phenomenon can be used to improve the design of the crystallization step in order to achieve more efficient downstream operations and, in general, to help optimize the whole manufacturing process.

\section{Shape evolution of succinic acid crystals}
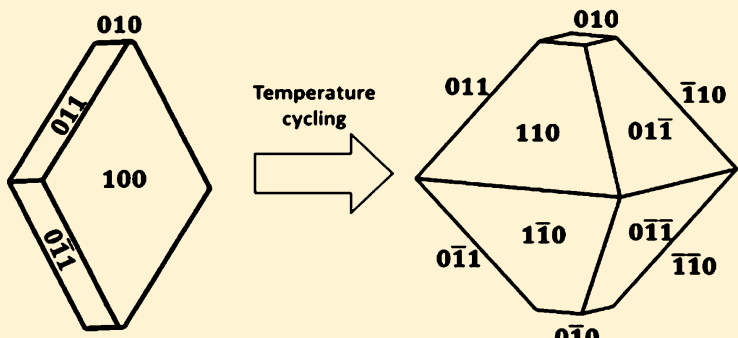

$0 \overline{10}$

\section{INTRODUCTION}

The size and shape of crystals have a profound effect on the properties of the final solid-form product as well as on the efficiency of downstream operations. Needles and plate-like crystals are usually considered undesirable since they are difficult to filter and suspend in solution. Fine crystals can also be problematic during filtration despite their faster dissolution rate. ${ }^{1-3}$

Including additives during the crystallization process can be effective in modifying the shape of the final crystals and reducing their aspect ratio, producing improved crystal shapes that enable more effective operation of downstream processes such as filtration. ${ }^{4-10}$ Additives can also be used to enable access to new or elusive polymorphic forms. ${ }^{11,12}$ Polymers may be selected as additives in preference to the alternative strategy of employing structurally similar additives because many polymers are generally recognized as safe (GRAS) compounds, and they cannot easily be incorporated in the crystal structure as impurities due to their large size. ${ }^{13-15}$

Crystal size and shape can also be manipulated through temperature cycling: heating and cooling cycles allow dissolution of fines and growth of the larger crystals; ${ }^{16-18}$ temperature

cycling was also found to affect the surface properties of the resulting crystals ${ }^{19}$ as well as the degree of solvent inclusion. ${ }^{20,21}$ This procedure was applied to both batch and continuous crystallization processes in a mixed suspension mixed product removal (MSMPR) configuration. ${ }^{22,23}$ Furthermore, the presence of regions of heating and cooling in a plug flow crystallizer was found to prevent fouling as well as improve crystal size distribution of the final product. ${ }^{24,25}$

Prolonged temperature cycling can also have a large impact on the shape of the original crystals, since different faces of the same crystal can have different relative growth and dissolution rates. Consecutive cycles of growth and dissolution can generate shapes that would be difficult or impossible to obtain by growth alone (e.g., linear, natural, or programmed cooling). ${ }^{26-29}$ The effect of temperature cycling on the shape of a single plate-like crystal was modeled and validated experimentally by Lovette et al. (2012), while Jiang et al. (2014) and Eisenschmidt et al.

Received: November 21, 2016

Revised: January 31, 2017

Published: March 9, 2017 


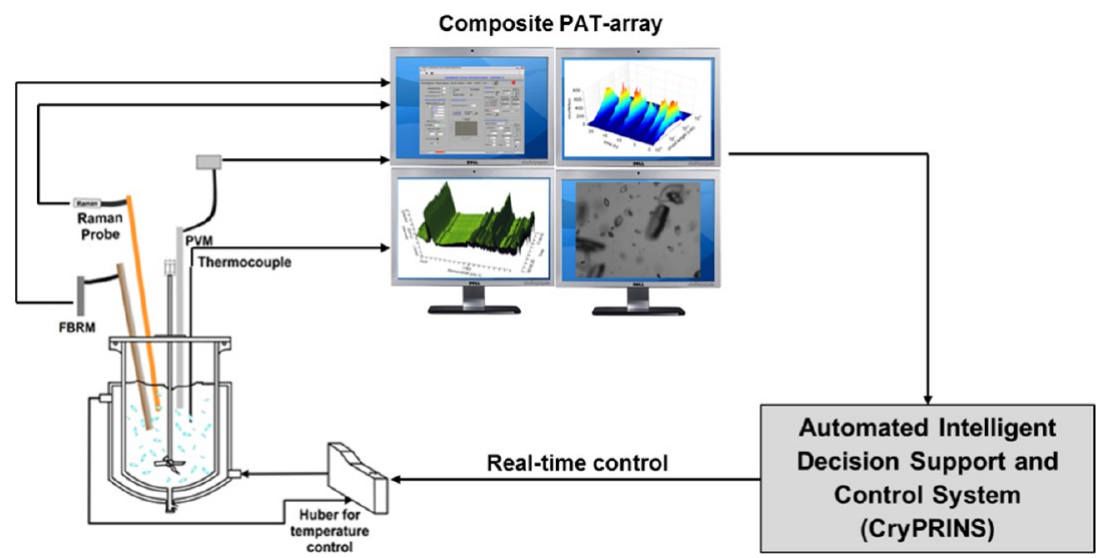

Figure 1. Schematic of the rig used for the experiments and the CryPRINS software.

(2015) both estimated the growth and dissolution kinetics using a multidimensional population balance model. ${ }^{29-31}$

In the first two studies a converging trend of the aspect ratio of crystals was experimentally observed during cycling for a single crystal and a population of crystals in a stirred vessel. However, experiments were not continued for long enough to observe a cycling equilibrium. In particular, Jiang et al. (2014) used focused beam reflectance measurement (FBRM), infrared spectroscopy (ATR-FTIR), and a particle vision and measurement (PVM) probe to determine the kinetic parameters during a single experiment in which crystals of monosodium glutamate were subjected to a deep but short temperature cycling (only five cycles). A considerable change in the shape of the crystal was observed together with changes in the FBRM statistics, but the experiment was stopped before any of them could reach a stable value. $^{30}$

Eisenschmidt et al. (2016) also optimized the number and amplitude of cycles during the crystallization process in order to achieve the desired shape of potassium dihydrogen phosphate (KDP) crystals. $^{32}$ Despite the simplicity of the model, which includes only dissolution and growth, and the imaging technique used for the estimation of the kinetic parameters, the study clearly shows how cycles of growth and dissolution can be used effectively to obtain morphologies that are not attainable by growth only.

In the work presented here, crystals of succinic acid have been subjected to different temperature cycles until the oscillating trends of shape and size distributions of the crystals did not change significantly over a relatively long period of time. Such a condition was determined using FBRM and PVM statistics as well as the Raman signal. This paper represents a first attempt to describe complex crystallization processes that include (1) primary and secondary nucleation, (2) complete dissolution of fine crystals and Ostwald ripening, (3) partial, face-specific, dissolution of large crystals, (4) face specific crystal growth. The result of such a process on a population of succinic acid crystals is a distinct change in morphology with the complete disappearance of a main crystallographic face, a reduction in the total number of suspended crystals, as well as a considerable increase in their mean size.

The effect of the type of cycling and the presence of a polymeric additive on the final shape of the crystals and the total time needed to reach the steady-state conditions was studied in this work. The existence of a practical steady-state size and shape of succinic acid crystals reached through temperature cycling was established, at the $350 \mathrm{~mL}$ scale. The time needed to reach this condition during the different types of cycling and in the presence of Pluronic P123 as a polymer additive was determined using the PAT tools employed (FBRM, PVM, and Raman spectroscopy), showing how crystal shape and size of succinic acid can be modified using a combination of temperature cycling and a polymeric additive. The results presented in this work can be used for a more efficient design of industrial batch crystallization processes that enhances the properties of the final product and reduces its production cost by specifically tailoring crystal shape and size.

\section{METHODOLOGY}

Succinic acid and Pluronic P123 were obtained from Sigma-Aldrich; deionized water (Millipore ultrapure water system) was used as the solvent for the experiments.

Succinic acid (SA) is a dicarboxylic acid commonly used as a coformer in multicomponent crystallization of active pharmaceutical ingredients (APIs) as well as in the food industry. ${ }^{33}$ It can exist in two polymorphic forms, $\alpha$ and $\beta$, which are enantiotropically related. The triclinic $\alpha$-form can be obtained by solid transformation from the $\beta$-form at temperatures above $137^{\circ} \mathrm{C} .{ }^{34}$ The monoclinic $\beta$-form can be crystallized from several solvents in different morphologies, ${ }^{35,36}$ and is the form studied here. Aqueous crystallization results in plate-like crystals, whereas crystallization from isopropanol results in a needle-like morphology. ${ }^{35-38}$ Pluronic P123 is a triblock copolymer with blocks of hydrophilic polyethylene glycol (PEG) sandwiching a hydrophobic polypropylene glycol (PPG) block.

The $350 \mathrm{~mL}$ cooling crystallizations were carried out using a $400 \mathrm{~mL}$ jacketed glass vessel equipped with overhead stirring at $325 \mathrm{rpm}$ (PTFE pitch blade turbine). The temperature was controlled using a PT-100 temperature probe connected to a Huber Ministat 230 thermoregulator. An RXN2 Hybrid Raman analyzer with immersion probe and $785 \mathrm{~nm}$ laser (Kaiser with iC Raman 4.1 software) was used during the experiments, together with a D600L Lansentec FBRM probe (equipped with control interface software version 6.7) and a particle vision and measurement (PVM) V819 probe (Mettler Toledo) with an online image acquisition software (version 8.3). The pre- and postprocessing of the data were done with Matlab R2013, iC Raman 4.1, and Excel 2010. The data from the FBRM and the Huber are transmitted in real-time to the CryPRINS software (Crystallisation Process Informatics System), which allows real time temperature control and simultaneous monitoring of signals from different probes (FBRM, ATR-UV/vis, thermocouple, conductivity probes, and $\mathrm{pH}$-meter).

Solutions of succinic acid in water (saturation temperature of $20^{\circ} \mathrm{C}$, corresponding to $0.06 \mathrm{~g} / \mathrm{g}$ water) were heated up to $30{ }^{\circ} \mathrm{C}$ to allow complete dissolution of the solids and then cooled down to $10{ }^{\circ} \mathrm{C}$ at a rate of $-0.5{ }^{\circ} \mathrm{C} / \mathrm{min}$ in order to nucleate crystals. The temperature was kept constant until the total counts/s measured by FBRM reached a stable value, and, after that, temperature cycling was started. The solution concentration and cooling rate were chosen after few 


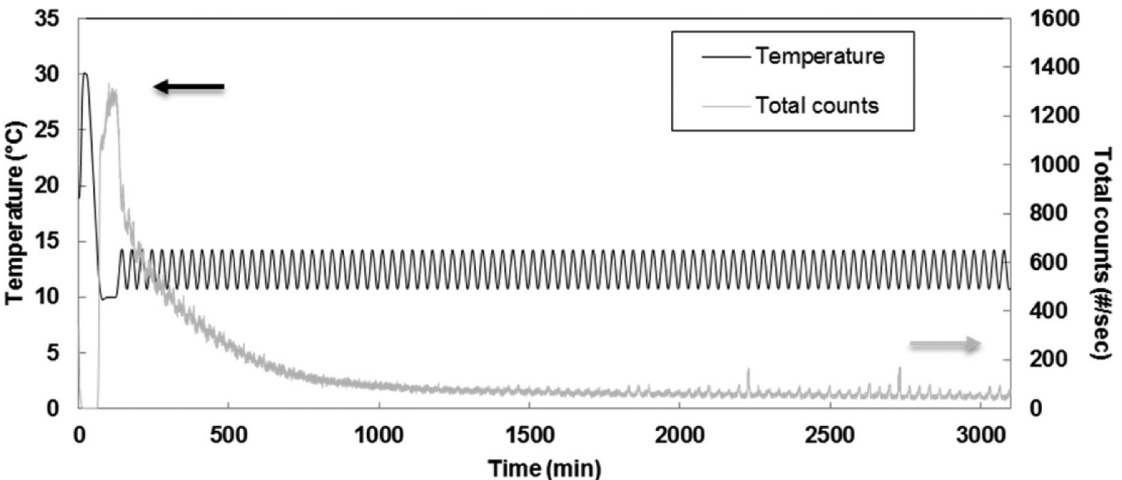

(a)

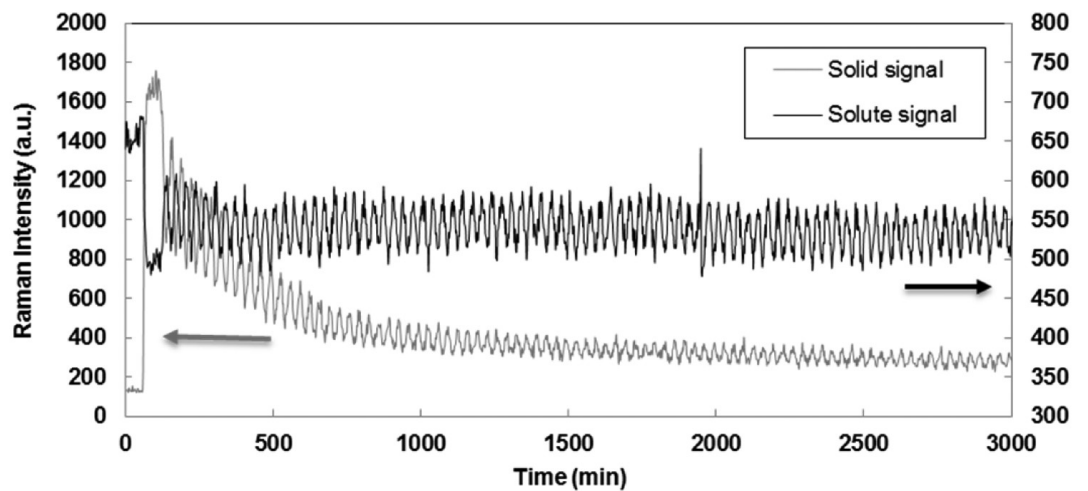

(b)

Figure 2. (a) Total counts/s from FBRM and (b) Raman signal for a cycling experiment $\left(4.5^{\circ} \mathrm{C}\right.$ amplitude and no additive).

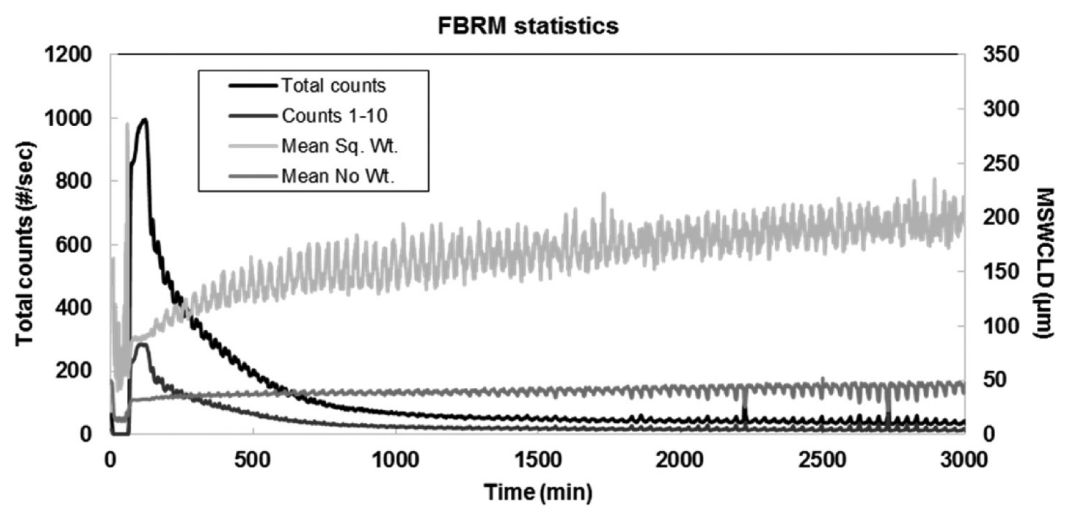

(a)

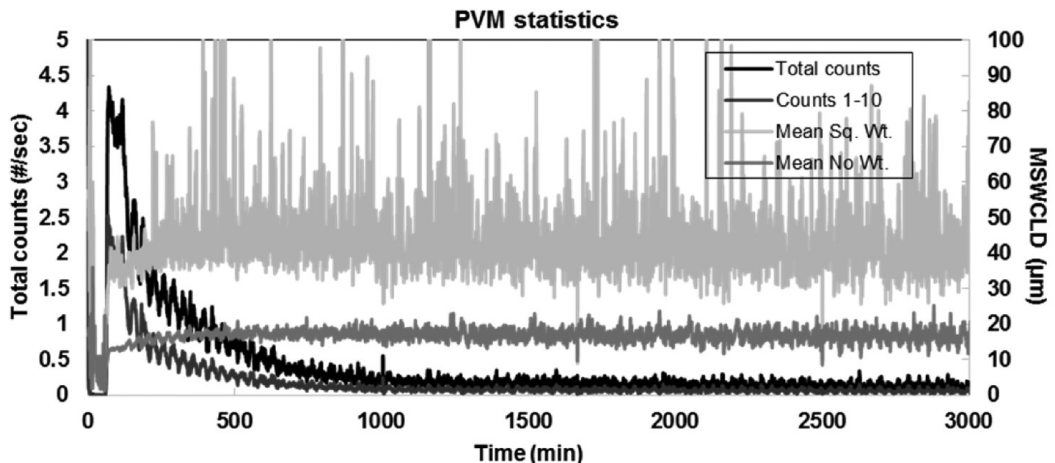

(b)

Figure 3. (a, b) Comparison between FBRM and PVM statistics for the same cycling experiment $\left(4.5^{\circ} \mathrm{C}\right.$ amplitude and no additive). The difference in scale in the two graphs is due mainly to the different size of the focusing area for the two instruments. Furthermore, in order to improve the quality of the PVM images a plastic lid is normally inserted at the end of the probe to reflect the light back to the camera. The presence of this obstacle decreases the number of particles that this probe can measure compared to FBRM. 
preliminary experiments that confirmed that nucleation temperature and crystal shape are not significantly affected by the rate of cooling at the level of supersaturation used for the experiments (Supporting Information). Furthermore, a low level of saturation was chosen to minimize crystal breakage and obtain a regular shape distribution before starting the temperature cycling.

The effects of the cycles' amplitude, heating/cooling rates, presence of the additive, and nonfixed cycling were studied. Experiments in each case were stopped when the statistics from FBRM and PVM reached fairly constant oscillating values.

In order to determine the effect of cycles' amplitude, a constant heating/cooling rate of $\pm 0.3{ }^{\circ} \mathrm{C} / \mathrm{min}$ was used, and three different cycling amplitudes $\left(4.5,6\right.$, and $\left.7.5^{\circ} \mathrm{C}\right)$ were tested. The effect of heating/cooling rate was studied by cycling crystals with $4.5{ }^{\circ} \mathrm{C}$ amplitude cycles at rates $\pm 0.1, \pm 0.3$, and $\pm 0.5{ }^{\circ} \mathrm{C} / \mathrm{min}$. The $4.5^{\circ} \mathrm{C}$ amplitude cycle, with $\pm 0.3{ }^{\circ} \mathrm{C} / \mathrm{min}$ heating/cooling rate, experiment was then repeated in the presence of Pluronic P123 at 1:200 and $1: 400 \mathrm{w} / \mathrm{w}$ polymer/succinic acid ratios, to investigate the effect of polymer additive on the resulting crystal morphology.

Fixed cycles at different amplitudes were compared to converging cycles (direct nucleation control, DNC). The DNC procedure is based on the combined use of FBRM and CryPRINS to keep the number of crystals in the vessel constant during a batch cooling crystallization, in order to promote their growth. One of the statistics (usually total counts/s) measured by the FBRM is sent to CryPRINS, and temperature is decreased if the measured total counts/s is lower than the set point range, or increased if it is higher (crystals in excess are then dissolved). Total counts/s set point, heating and cooling rates can be selected in CryPRINS. The concept of DNC has been successfully used for both pharmaceutical and biopharmaceutical compounds..$^{17,18,39,40}$

Two set points were chosen for pure succinic acid: 50 and 100 \#/s based on the number of counts reached at the steady-state conditions in the fixed-cycle experiments. The lower set point was also tested in the presence of Pluronic P123 additive in a ratio of $1: 400 \mathrm{w} / \mathrm{w}$ to succinic acid. A heating/cooling rate of $\pm 0.3^{\circ} \mathrm{C} / \mathrm{min}$ was used for the additive experiment, while a $\pm 0.2{ }^{\circ} \mathrm{C} / \mathrm{min}$ rate was applied to the two experiments in the absence of additive.

Samples of 5-6 mL were taken during the cycles and observed in an optical microscope. Furthermore, their polymorphic form was checked by Raman microscopy and single crystal X-ray diffraction was carried out to index the faces of each analyzed crystal.

Face indexing of the crystals was carried out using a Rigaku Oxford Diffraction (formerly Agilent Technologies) Xcalibur diffractometer with $\mathrm{Mo}-\mathrm{K} \alpha(\lambda=0.71073 \AA)$ radiation, equipped with an optical camera to select the faces. The CrysAlisPro 171.37.33 software was used to index the crystal faces. Mercury $3.5^{41}$ was used to calculate the Bravais-Friedel-Donnay-Harker (BFDH) morphology and to determine the molecular arrangement at the facet surfaces.

\section{RESULTS AND DISCUSSION}

Initial Cycling Experiment. An aqueous solution of succinic acid (saturation temperature of around $20{ }^{\circ} \mathrm{C}$ ) was heated up until complete dissolution of the solid and then cooled down to $10{ }^{\circ} \mathrm{C}$ at a rate of $-0.5{ }^{\circ} \mathrm{C} / \mathrm{min}$. After nucleation, heating and cooling cycles of $4.5^{\circ} \mathrm{C}$ amplitude were applied to the solution for about two consecutive days, until the oscillating trends for shape and size distributions of the crystals did not change significantly over a relatively long period of time (around $500 \mathrm{~min}$ ). This can be considered a "practical" steady state, and it was identified by the observation of PVM and FBRM statistics as well as the Raman signal. This condition will be referred to simply as "steady-state" in the rest of this paper. The evolution of the system for longer times (weeks or years of cycling) is not the aim of this work, and it would likely require the use of simulations tools, since such long experiments are quite unpractical.

Figure 2a shows the temperature profile and the total counts/s recorded from FBRM: an oscillating trend can be observed
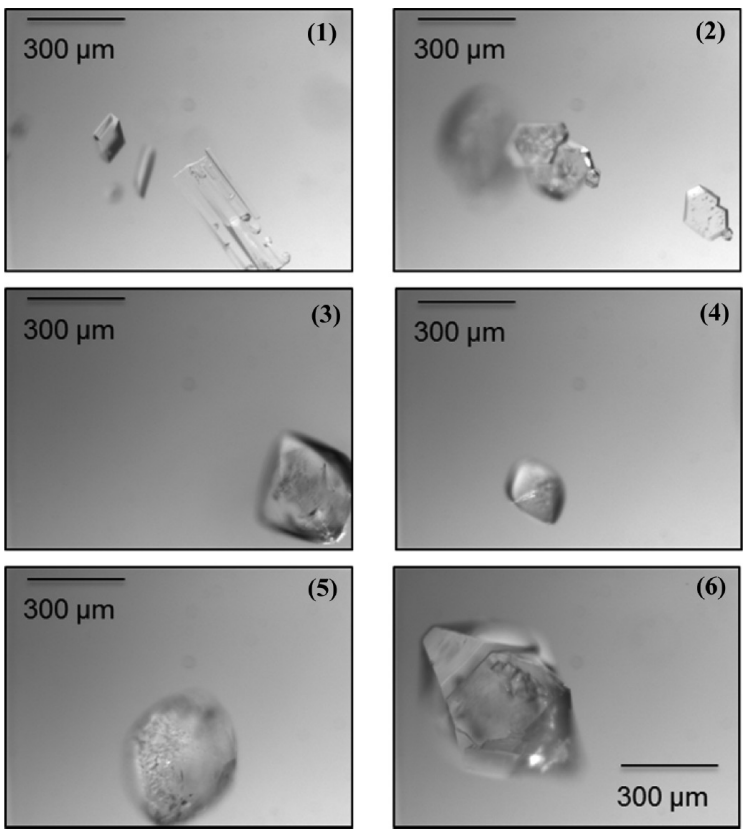

Figure 4. PVM images of succinic acid crystals during the temperature cycling experiment with $4.5{ }^{\circ} \mathrm{C}$ cycling amplitude and $\pm 0.3{ }^{\circ} \mathrm{C} / \mathrm{min}$ heating/cooling rates. Images taken at (1) $100 \mathrm{~min}$ after initial cooling to $10{ }^{\circ} \mathrm{C}$; (2) $210 \mathrm{~min}$, heating step; (3) $360 \mathrm{~min}$, heating step; (4) $660 \mathrm{~min}$, heating step; (5) $915 \mathrm{~min}$, heating step; and (6) $1070 \mathrm{~min}$, cooling step.
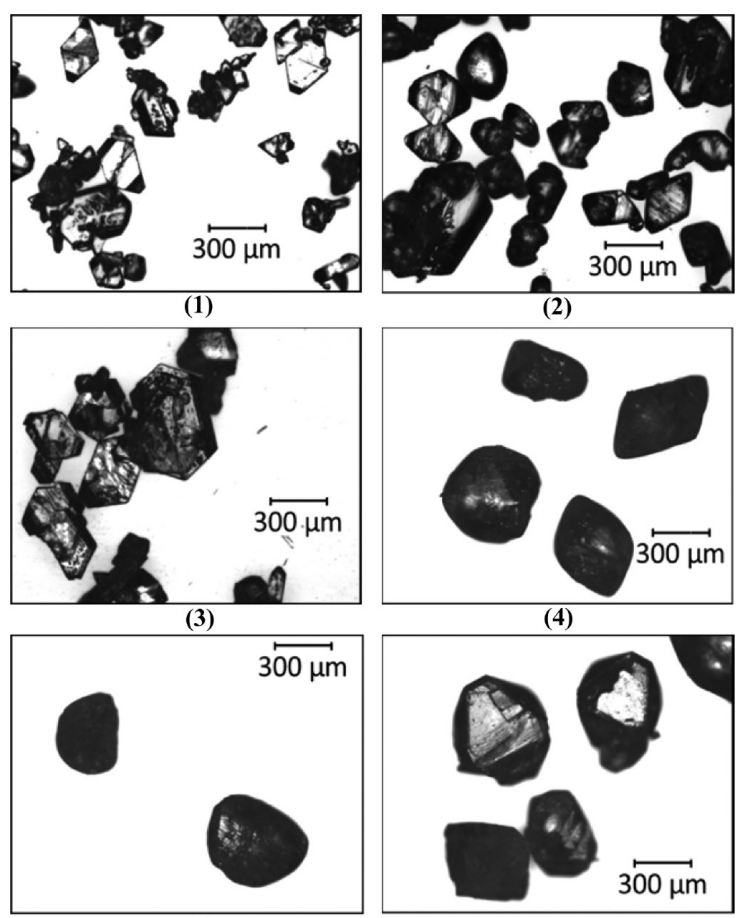

(5)

(6)

Figure 5. Microscopic images of samples at (1) $120 \mathrm{~min}$, constant temperature at $10{ }^{\circ} \mathrm{C}$; (2) $270 \mathrm{~min}$, heating step; (3) $425 \mathrm{~min}$, cooling step; (4) $1260 \mathrm{~min}$, cooling step; (5) $1600 \mathrm{~min}$, cooling step; (6) final crystals after cooling $(2990 \mathrm{~min})$.

for the total counts/s indicating the presence of secondary nucleation during the cooling steps of the cycles, for the whole duration of the experiment. However, secondary nucleation is counterbalanced by dissolution, growth, and Ostwald ripening 

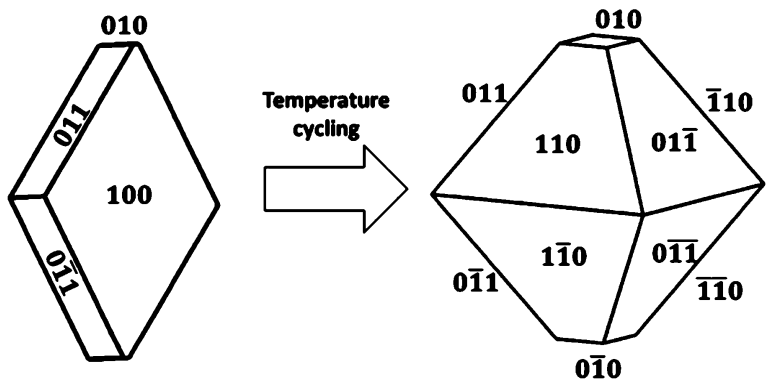

Figure 6. Change in morphology of succinic acid crystals during temperature cycling.

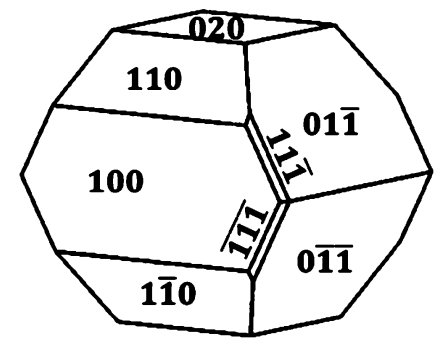

Figure 7. BFDH calculated morphology of $\beta$-succinic acid.

which contribute to an overall decrease in the total counts down to around 50 \#/s. The smaller particles generated by both primary and secondary nucleation are preferentially dissolved during the heating phases allowing further growth of the larger ones during cooling. Primary nucleation generates a large amount of fines that are dissolved and incorporated into the largest crystals during the cycles in the first 1500-2000 min of the experiment. This generates a rapid decrease in the number of crystals in solution and a quick increase in the mean crystal size. Toward the end of the experiments almost all the fines produced by the initial primary nucleation have been dissolved and incorporated in the larger crystals; the following heating steps primarily dissolve fines produced by secondary nucleation. Dissolution, growth, and secondary nucleation are the main phenomena in the presented static cycling experiments, while Ostwald ripening is believed to play only a secondary role. In fact, this phenomenon becomes relevant at low supersaturations, when nucleation is not predominant anymore; ${ }^{42,43}$ the presence of temperature cycles that periodically create high supersaturation as well as secondary nucleation distances the studied system from this condition. Furthermore, when a narrow size distribution with large mean size is achieved, Ostwald ripening is practically negligible. ${ }^{44}$

These considerations are confirmed by the trends for both PVM and FBRM main statistics, shown in Figure 3a,b. Total counts/s and fines counts (1-10 $\mu \mathrm{m}$ chord length) are shown together with the mean of the chord length distribution (CLD) and the mean of the square weighted chord length distribution (SWCLD). While the counts of fines and total particles is decreasing, the means of the CLD and the SWCLD are increasing as a result of the growth of the succinic acid crystals.
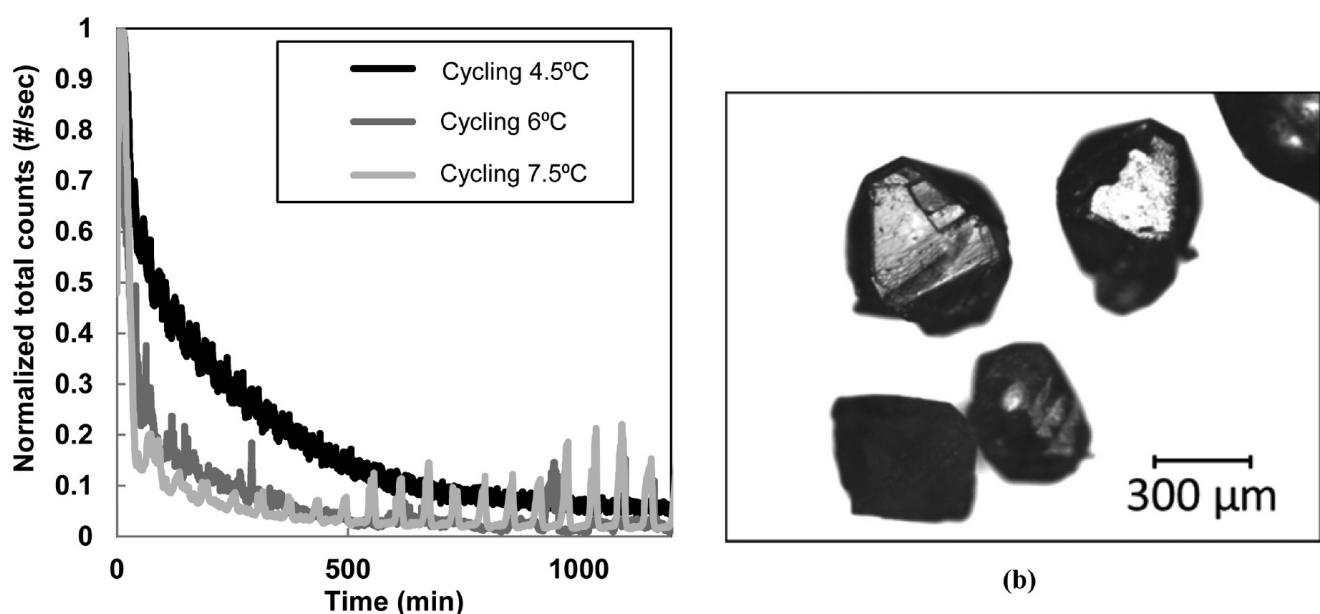

(a)
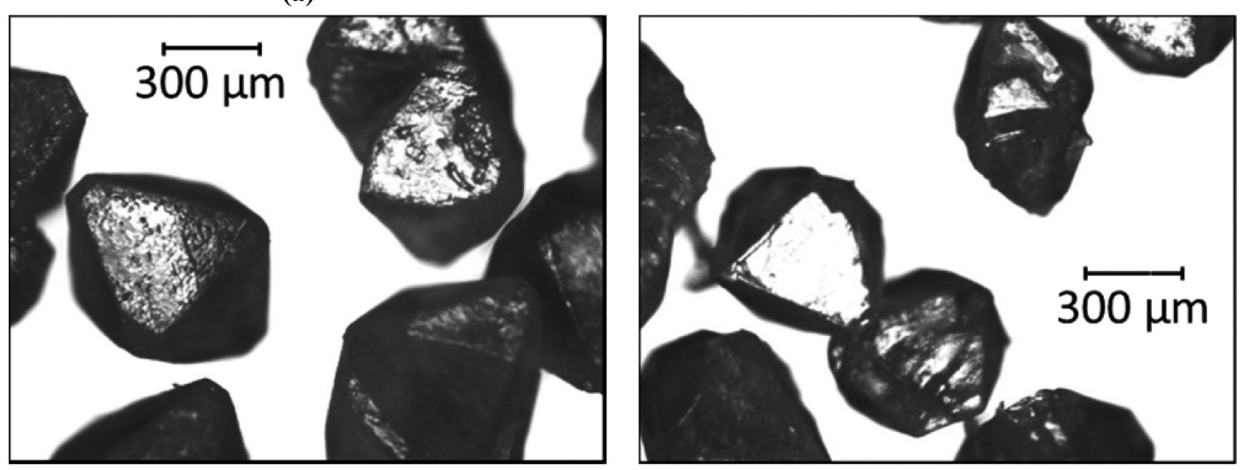

(c)

(d)

Figure 8. (a) Trends of the total counts/s (values normalized to 1 ) for cycling experiments at different cycle amplitudes; crystals obtained at the end of experiments (cooling step) at (b) $4.5^{\circ} \mathrm{C}$ amplitude cycling (2990 min); (c) $6{ }^{\circ} \mathrm{C}$ amplitude cycling (1470 min); and (d) $7.5^{\circ} \mathrm{C}$ amplitude cycling $(1500 \mathrm{~min})$. 

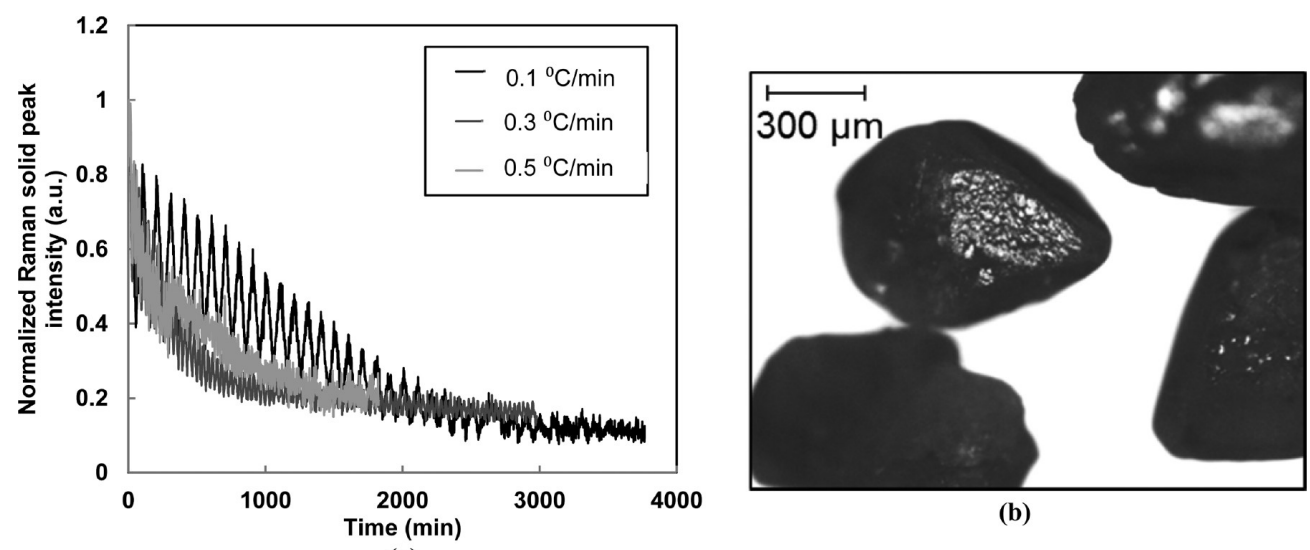

(a)
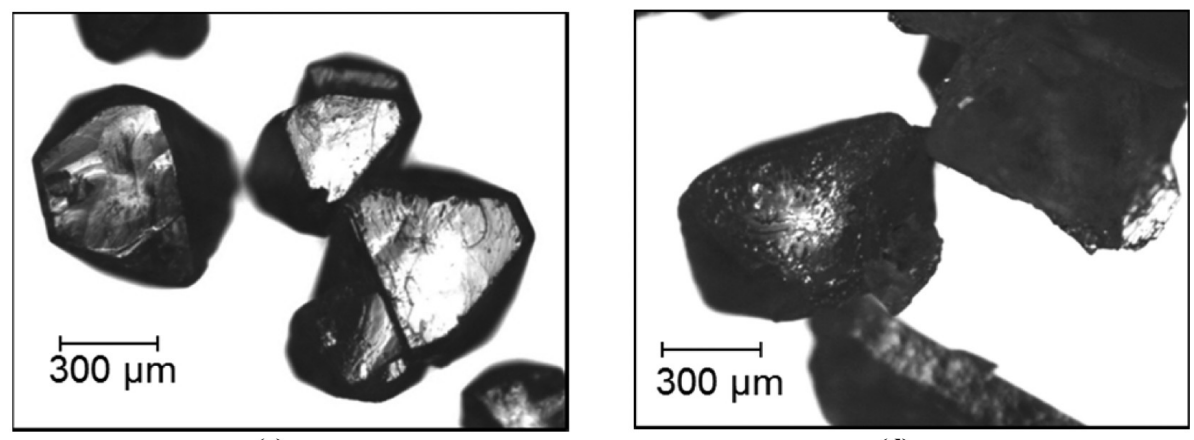

(c)

(d)

Figure 9. Effect of temperature cycling at different heating cooling rates: (a) Raman signal for the solid peak of succinic acid for temperature cycling experiments at $\pm 0.1, \pm 0.3$, and $\pm 0.5^{\circ} \mathrm{C} / \mathrm{min}$; (b) microscopic images of crystals obtained after cycling at $\pm 0.1{ }^{\circ} \mathrm{C} / \mathrm{min}$; (c) microscopic images of crystals obtained after cycling at $\pm 0.3{ }^{\circ} \mathrm{C} / \mathrm{min}$; (d) microscopic images of crystals obtained after cycling at $\pm 0.5^{\circ} \mathrm{C} / \mathrm{min}$.

It is worth noting that the trends from the two instruments are very similar, and the data from the PVM presents relatively small noise compared to other systems tested with the same probe. ${ }^{45,46}$

Figure $2 \mathrm{~b}$ shows the trend of two Raman peaks, one for the solute $\left(840 \mathrm{~cm}^{-1}\right)$ and one for the solid particles $\left(937 \mathrm{~cm}^{-1}\right)$. Second derivative and smoothing were applied to all Raman spectra for a better peak identification. While the intensity of the solute peak oscillates between the same minimum and maximum values, the peak corresponding to the solids decreases over time even though it continues to oscillate. During the cycles the number of particles decreases while their size increases as a result of the dissolution of the fine particles. Clearly, the intensity of the solid peak is inversely proportional to the size of the particles and/or directly correlated to their number. While it is easy to understand the effect of cycling on the size and number of the crystals by observing the PVM and FBRM statistics, obtaining quantitative information on the change in crystal shape for this system is not possible.

PVM images can give an indication of a change in shape of the crystals, as shown in Figure 4: crystals move from irregular plates to a tridimensional diamond shape. This change indicates that the heating steps contribute to both the complete dissolution of fine crystals produced by primary and secondary nucleation as well as partial dissolution of the larger particles, which allows the observed morphology evolution.

Furthermore, microscopic images of the crystals extracted during the cycling are shown in Figure 5: the shape is initially plate-like, but it gradually converts to diamond-like. The diamond crystals are easier to filter and present a higher uniformity in shape compared to the particles obtained before cycling.
Since it is difficult to determine the exact crystal morphology by examining two-dimensional images, the faces of few filtered and dried crystals from the experiments were indexed thus studied using single crystal X-ray diffraction.

The result of face indexing a diamond shaped succinic acid crystal is shown in Figure 6. The same figure also shows the face indexing of an early nucleated plate-like crystal for comparison. It is evident that cycling promotes the growth of the (110) and $(1 \overline{1} 0)$ faces over the (100) face which is prominent in the platelike crystals that nucleated before cycling. The (100) face intercepts chains of succinic acid molecules linked by carboxylic acid dimers; it is, therefore, a polar face with which water easily interacts. That explains why this face is normally prominent in the succinic acid crystals nucleated and grown in water. Temperature cycling seems to help in overcoming the inhibiting effect of the solvent on the growth of the (100) face.

While the plate-like shape with predominant (100) face has often been found as the most common morphology for succinic acid crystals grown from water via both experiments ${ }^{33,35,38}$ and modeling work, ${ }^{28,36,37}$ diamond shaped crystals of succinic acid obtained from water have never been observed before.

In addition, it is interesting to note that the final steady-state shape produced from the temperature cycling experiments presented here is more comparable with the equilibrium shape calculated by the Bravais-Friedel-Donnay-Harker (BFDH) approach (shown in Figure 7) than the morphology produced in the absence of temperature cycling. While the (100) face is present in the BFDH model, it is less dominant and the (110) and (110) faces featured in the crystals produced from temperature cycling are also present. 

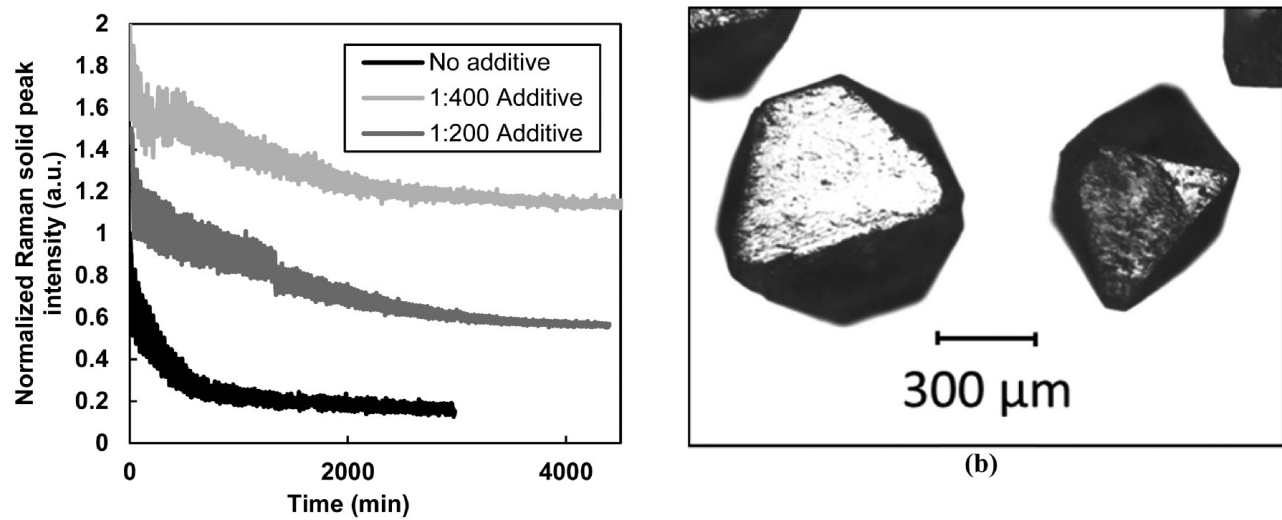

(b)

(a)

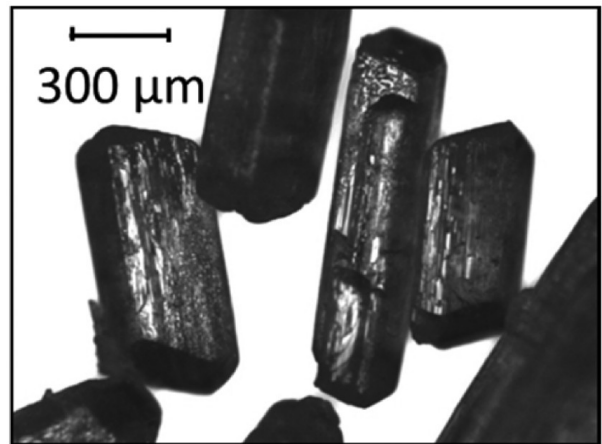

(c)

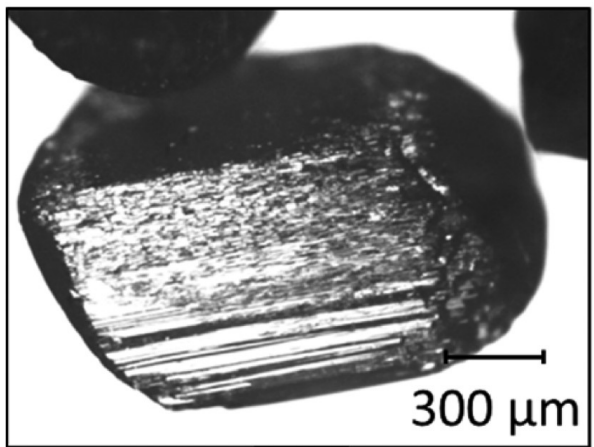

(d)

Figure 10. (a) Trends of the Raman peak related to solid succinic acid (values normalized to 1 ) for cycling experiments at different additive concentrations; (b) crystals obtained at the end of the cycling experiment in the absence of additive ( $2980 \mathrm{~min})$; (c) crystals obtained at the end of the cycling experiment with 1:400 additive/SA weight ratio (4390 min); and (d) crystals obtained at the end of the cycling experiment with 1:200 additive/ SA weight ratio (4610). The trends were stacked in the plot to avoid overlapping of signals.

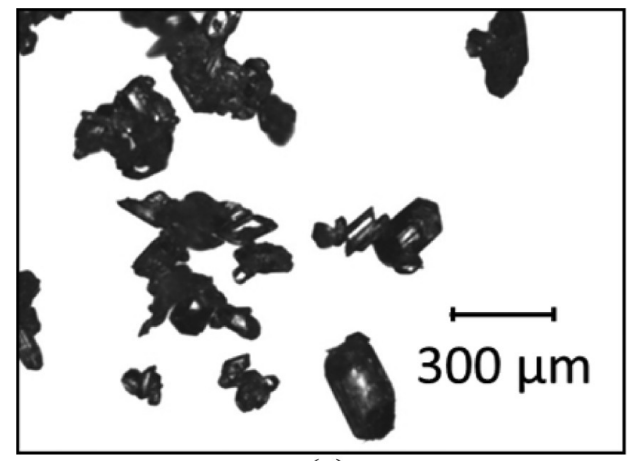

(a)

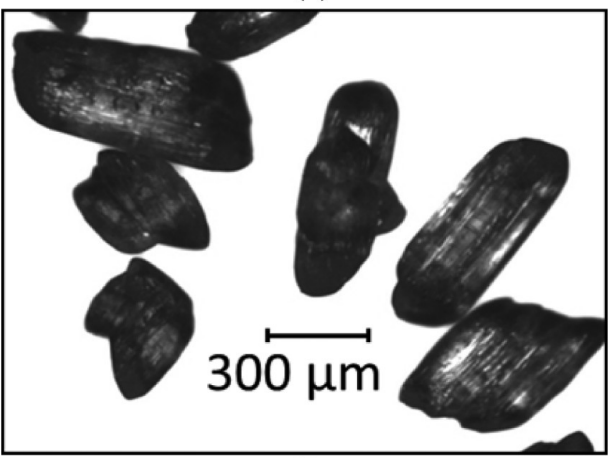

(c)

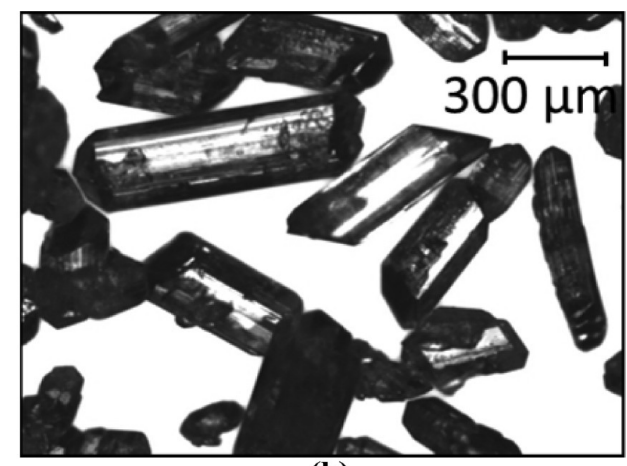

(b)

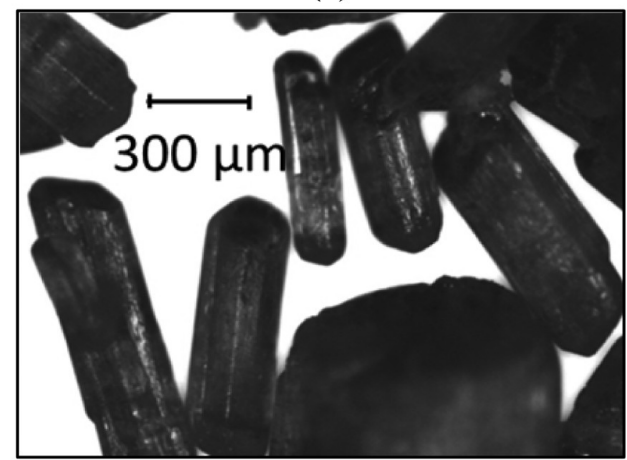

(d)

Figure 11. Microscopic images of samples during the cycling experiment performed in the presence of 1:400 additive/SA weight ratio; (a) initial crystals before cycling, collected at constant temperature of $10^{\circ} \mathrm{C}(0 \mathrm{~min})$; (b) heating step (1045 min); (c) heating step (1480 min); and (d) final crystals, cooling step. 
Different Amplitudes Cycling. Three different cycling amplitudes $\left(4.5,6\right.$, and $7.5{ }^{\circ} \mathrm{C}$ ) were tested using a heating/ cooling rate of $\pm 0.3{ }^{\circ} \mathrm{C} / \mathrm{min}$. Figure 8 shows the final shape of the crystals obtained during the three runs as well as the trends of the total counts/s over time.

All crystals have the same diamond shape at the end of the experiments despite the different operating conditions. The time required to obtain a stable oscillating trend of the total counts/s seems to increase with decreasing the amplitude of the cycles; larger cycles of heating and cooling allow a faster dissolution of the small particles and a quicker adjustment to the steadystate shape. An increase in the maximum number of counts during the oscillations for the cooling phases in the cycling experiments at $7.5{ }^{\circ} \mathrm{C}$ amplitude; this is due to both secondary nucleation of new small particles and partial sedimentation of the bigger crystals, which tend to "expose" the smaller crystals to the FBRM laser beam. Fouling on the probe has to be excluded in this case since the trend of the total counts/s recorded with the PVM was similar to that from the FBRM and images did not show any sticking particles on this probe. Furthermore, several fines particles can be observed in the PVM images toward the end of the experiment.

Different Cooling/Heating Rate. The effect of different heating/cooling rates on the shape of the succinic acid crystals and the time to reach a steady-state condition was evaluated by three temperature cycling experiments at $\pm 0.1, \pm 0.3$, and $\pm 0.5{ }^{\circ} \mathrm{C} / \mathrm{min}$. Figure 9 shows the results for the three experiments; the time needed to reach the steady-state condition is determined by the observation of the Raman signal of the peak for solid succinic acid, shown in Figure 9a. Faster rates allow a constant oscillating value to be reached more quickly; at $\pm 0.5{ }^{\circ} \mathrm{C} / \mathrm{min}$ only $1500 \mathrm{~min}$ are needed to reach a stable Raman signal, while it takes over $4000 \mathrm{~min}$ if the cycling rates are $\pm 0.1{ }^{\circ} \mathrm{C} / \mathrm{min}$. However, the microscopic images of the three samples (Figure $9 \mathrm{~b}-\mathrm{d}$ ) show considerable differences in the shape of the crystals and, in particular, in its homogeneity.

Particles obtained at faster heating/cooling rates (Figure 9d) have a more irregular diamond shape compared to those obtained at slower rates (Figure 9b,c). It is likely that the fast cycling does not allow enough time for the rearrangement of the shape (especially for larger particles) resulting in inhomogeneity within the crystals population.

The slight shift in the Raman signal for the experiment at rates of $\pm 0.5^{\circ} \mathrm{C} / \mathrm{min}$ is due to an involuntary change in the position of the Raman probe within the vessel which did not influence the Raman signal from the solute.

Effect of the Additive on the Steady-State Conditions. The effect of the polymer additive Pluronic P123 on the shape of succinic acid crystals during cycling experiments was also tested.

Figure $10 \mathrm{~b}-\mathrm{d}$ shows images of the crystals obtained at the end of cycling experiments both in the absence of additive and in its presence, at weight ratios of 1:200 and 1:400 over the total succinic acid in the vessel. The steady-state shape in the presence of the additive is rod-like in contrast to the diamond shape obtained without additive. Figure 10a shows the trends for the normalized Raman solid peak intensity during the experiments conducted at different concentrations of polymer: the time necessary to reach a steady state condition is longer in the presence of the additive. The difference in shape and the longer time needed to stabilize the Raman signal is due to the inhibiting effect of Pluronic P123 on the growth of succinic acid, which has been observed elsewhere, ${ }^{38}$ where the effect on particle morphology of differing concentrations of both succinic acid and polymer was studied. It is worth noting that this polymeric additive is able to modify the shape of succinic acid without being incorporated in the crystal structure as shown in the same work. $^{38}$

The two experiments conducted in the presence of additive present interesting trends of the total counts/s, CLD and FBRM statistics because of secondary nucleation and growth in length of the rod-like crystals. The full set of data and detailed explanation is shown in the Supporting Information (SI2).

Figure 11 shows the evolution of the crystals during the cycling experiment conducted at a $1: 400 \mathrm{w} / \mathrm{w}$ ratio of additive over succinic acid. The size of the particles clearly increases but the shape does not seem to change while cycling; crystals remain rodlike during the whole experiment. The presence of the additive prevents the shape evolution of succinic acid crystals into diamonds during the temperature cycling.

Figure 12 shows the results of the face indexing: the presence of the additive inhibits growth of the crystals in the direction

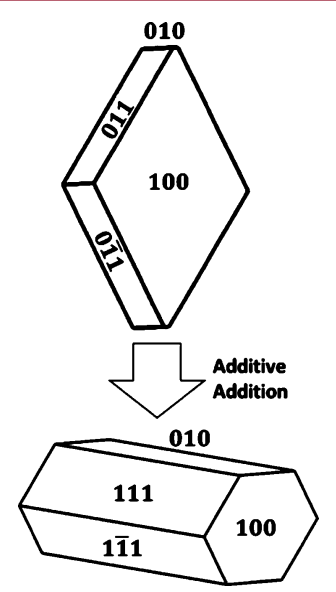

Figure 12. Change in succinic acid morphology of succinic acid in the presence of an additive (Pluronic P123).

perpendicular to the (111) and (1 $1 \overline{1} 1)$ faces, resulting in a rod-like shape with the elongation along the crystallographic $a$-axis.

Convergent Cycling (DNC). Automated temperature cycling of decreasing amplitude, based on the value of the total counts/s recorded from FBRM (direct nucleation control, DNC), was also applied to the growth of succinic acid crystals.

This strategy was tested to investigate whether it is possible to obtain diamond shaped crystals with a large mean size, similar to what was observed in the static cycling experiments, but in less batch time.

The DNC is designed to keep the total counts/s at a specific set point by alternating heating cycles, which dissolve the fine particles and reduce the counts/s, and cooling cycles, which allow growth of the larger crystals as well as potential nucleation that leads to increase in the counts/s.

Two set points of 50 and $100 \# / s$ were chosen based on the values of the total counts/s at stationary conditions, determined in the experiments presented in the previous sections (see Figure 2a). Figure 13 shows the temperature profile, the trend for the total counts/s and the mean of the SWCLD for three different experiments. Figure 13 a shows the results for the experiment carried out in the absence of additive and with a total counts/s set point of $100 \mathrm{\#} / \mathrm{s}$. The experiment shown in Figure $13 \mathrm{~b}$ was conducted without Pluronic P123 present and at a set point of 50 \#/s, while for the 

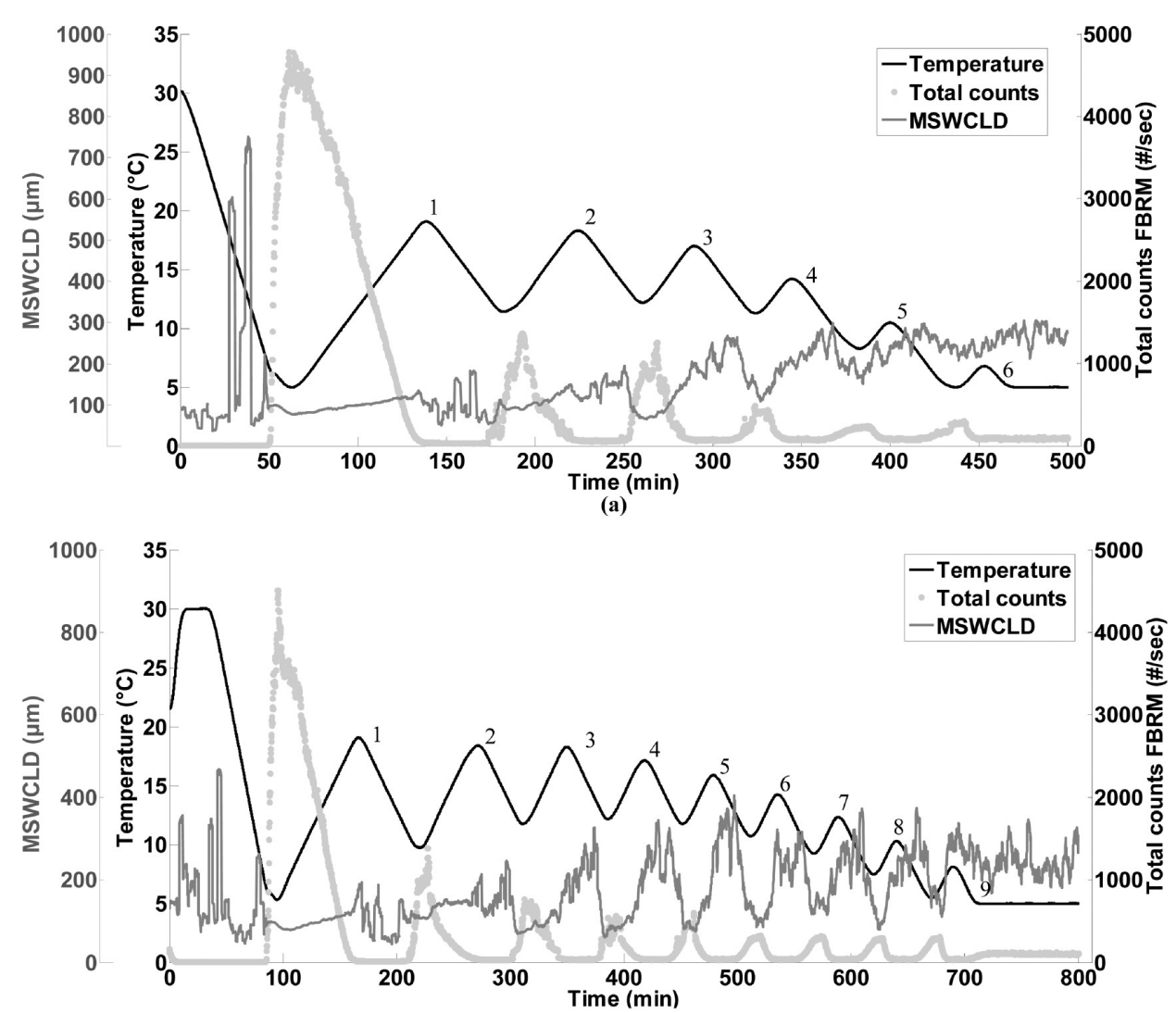

(b)

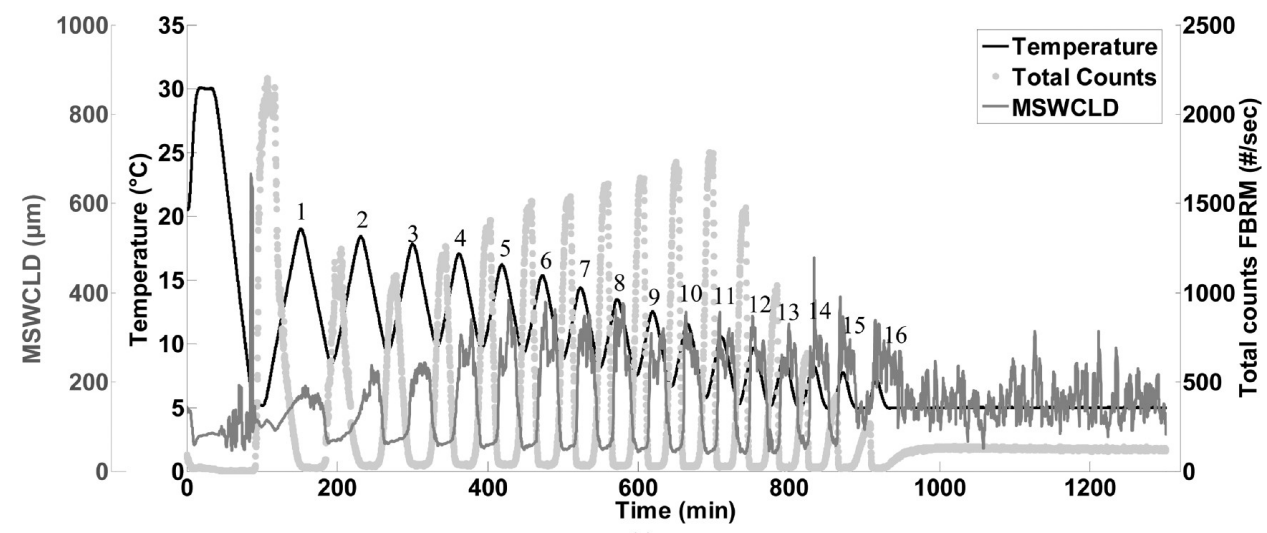

(c)

Figure 13. (a) Direct nucleation control (DNC) experiment with set point 100 \#/s, no additive, and heating/cooling rate $\pm 0.2^{\circ} 12 \mathrm{C} / \mathrm{min}$; $(\mathrm{b}) \mathrm{DNC}$ experiment with set point $50 \mathrm{\#} / \mathrm{s}$, no additive, and heating/cooling rate $\pm 0.2^{\circ} \mathrm{C} / \mathrm{min}$; (c) DNC experiment with set point 50 \#/s, with additive in $1: 400$ ratio, and heating/cooling rate $\pm 0.3{ }^{\circ} \mathrm{C} / \mathrm{min}$.

experiment of Figure $13 \mathrm{c}$ a weight ratio polymer/succinic acid of 1:400 was used. As expected a lower set point required a longer batch time, and a higher number of temperature cycles was reached (six cycles with set point $100 \# /$ s versus nine cycles with set point $50 \mathrm{\#} / \mathrm{s})$.

Comparing Figure 13b,c it is evident that, in the presence of the additive, more cycles are required to reach the same total counts/s set point (16 cycles versus 9 ). This is due to the inhibiting effect of the polymer on the growth of succinic acid crystals. ${ }^{38}$ The total time necessary to reach the total counts/s set point is considerably lower than the time needed to reach stationary conditions with cycles of fixed amplitude. However, the final shape of the crystals is still plate-like (without polymer) and rod-like (with polymer) rather than diamond-like, as shown in Figure 14.
Figure 14a,b shows the crystals obtained at the end of the two DNC experiments carried out without additive. Crystals grew larger and more homogeneous in shape compared to the early nucleated crystals, but they still preserve mainly a plate-like shape (few diamond shaped crystals were identified in the samples taken during the experiment with 50 \#/s set point). The shape of the crystals nucleated in the presence of the polymer is rod-like, as observed in the previous runs. It is clear that, despite reaching the target total counts/s in less time compared to the static cycling experiments (Figures 2a, 8a, and 9a), the DNC strategy could not allow a uniform diamond shape to be obtained, as observed in the static cycling experiments. In order to reach this morphology, further temperature cycling had to be applied to the crystals while still in suspension. 


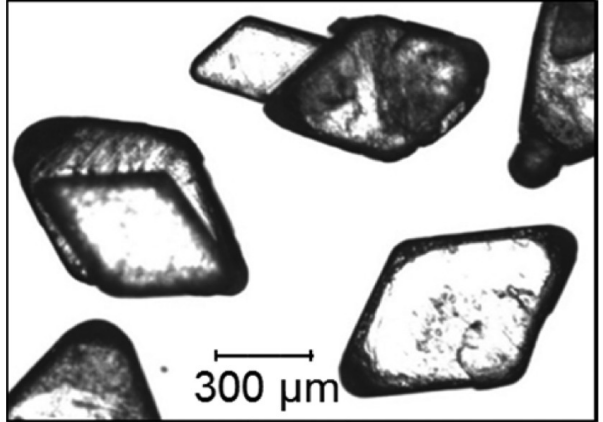

(a)

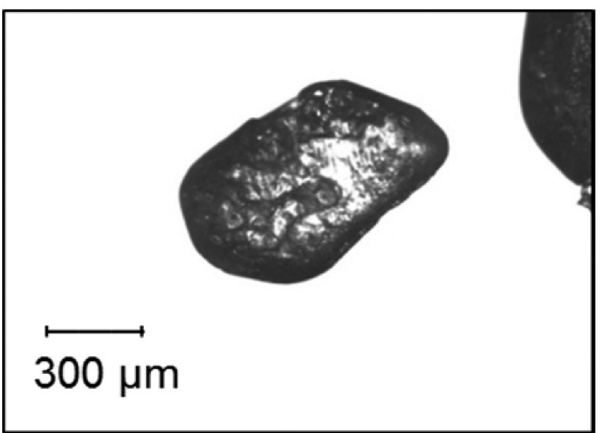

(c)

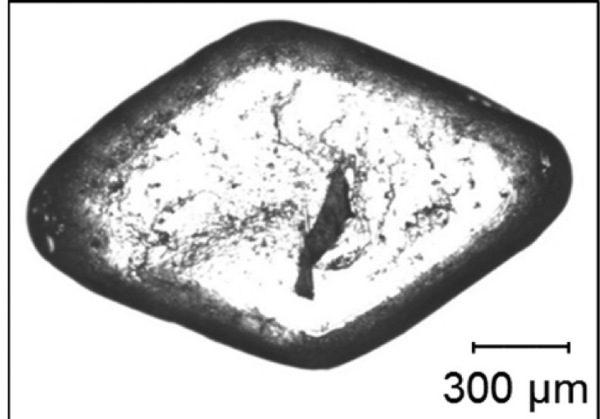

(b)

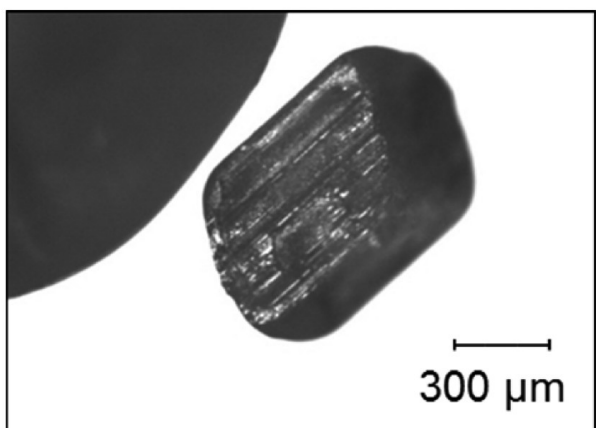

(d)

Figure 14. (a) Microscopic image of crystals obtained from direct nucleation control (DNC) experiment with set point 100 \#/s and no additive; (b) microscopic image of crystals obtained from DNC experiment with set point 50 \#/s and no additive; (c, d) microscopic images of crystals obtained from DNC experiment with set point $50 \# / s$ and additive in a 1:400 ratio.

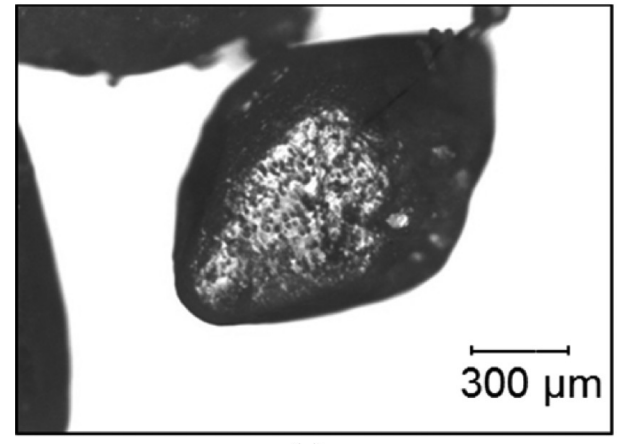

(a)

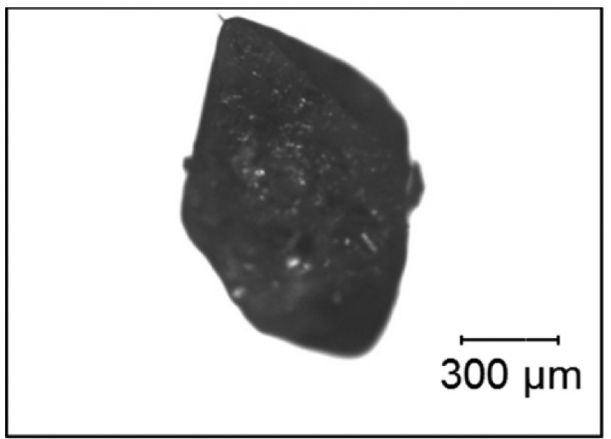

(c)

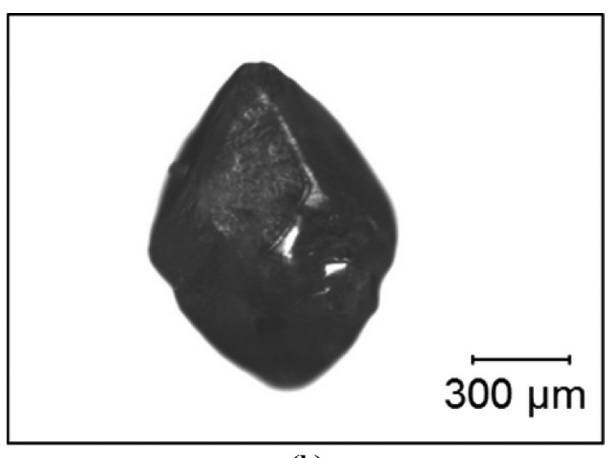

(b)

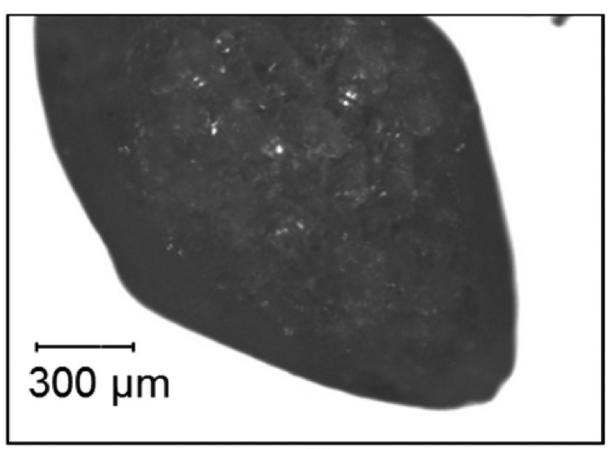

(d)

Figure 15. (a-d) Microscopic images of crystals obtained after direct nucleation control with set point 50 \#/s followed by cycling between 8.5 and $16{ }^{\circ} \mathrm{C}$ at a heating/cooling rate of $\pm 0.3^{\circ} \mathrm{C} / \mathrm{min}$ for $28 \mathrm{~h}$.

Figure 15 shows a few particles obtained after DNC at $50 \mathrm{\#} / \mathrm{s}$ set point followed by temperature cycling between 8.5 and $16^{\circ} \mathrm{C}$ at a heating/cooling rate of $\pm 0.3{ }^{\circ} \mathrm{C} / \mathrm{min}$ for $28 \mathrm{~h}$. Only the addition of temperature cycling after $\mathrm{DNC}$ allows the diamond shape to be reached uniformly in the whole crystal population, indicating that it is not possible to obtain the steady-state shape by forcing the counts to decrease to their steady state value using the feedback strategy alone. 


\section{CONCLUSIONS}

Temperature cycling can modify the shape and size of succinic acid crystals until a steady-state condition (that can be detected using PAT tools) is reached. The type of cycling and the presence of additives can dramatically change the characteristics of the particles at steady-state condition as well as the time necessary to reach them.

In the absence of an additive the shape of succinic acid crystals moves from plate-like, just after nucleation, to a diamond shape after temperature cycling. Both PVM and FBRM statistics change during the cycling and tend to reach steady-state values, which can help determine the time of the transient state. In the presence of Pluronic P123, succinic acid crystals do not change their shape during cycling but they increase in size. Particles remained rod-like during the whole process but grew until they reached a steady-state size distribution, detectable by both PVM and FBRM statistics.

It was found that increasing the amplitude of the cycles or the heating/cooling rates decreases the time necessary to reach a steady-state condition. However, imposing converging cycles by DNC modified the size but not the shape of the crystals, indicating the need for longer times for the evolution of the shape.

The ability to control the shape of the particles at the end of a crystallization process is essential for the improvement of downstream processes such as filtration, washing, and drying. The results of this work show how crystal shape can be modified by changes in temperature as well as by additives that are not incorporated in the solid. ${ }^{38}$ This gives a further strategy that can produce optimized particles without compromising the purity of the final product, offering routes to optimize successive unit operations in a process and achieve a higher quality product.

\section{ASSOCIATED CONTENT}

\section{S Supporting Information}

The Supporting Information is available free of charge on the ACS Publications website at DOI: 10.1021/acs.cgd.6b01683.

Metastable zone widths and succinic acid crystals images from batch cooling crystallization experiments performed at different cooling rate (PDF)

\section{AUTHOR INFORMATION}

\section{Corresponding Author}

*E-mail: znagy@purdue.edu.

\section{ORCID $\odot$}

Elena Simone: 0000-0003-4000-2222

Zoltan K. Nagy: 0000-0003-4787-6678

Notes

The authors declare no competing financial interest.

\section{ACKNOWLEDGMENTS}

This work is funded through the European Research Council Grant No. [280106-CrySys], EPSRC Grants EP/I033459/1 (CMAC Centre) and EP/K503289/1 (Doctoral Training Centre in Continuous Manufacturing and Crystallization).

\section{REFERENCES}

(1) Mullin, J. W. Crystallization, 5th ed.. Butterworth Heinemann, 2001.

(2) Chianese, A.; Kramer, H. J. M. Industrial Crystallization Process Monitoring and Control; WILEY-VCH, 2012.
(3) Nagy, Z. K.; Fevotte, G.; Kramer, H. J. M.; Simon, L. L. Chem. Eng. Res. Des. 2013, 91 (10), 1903-22.

(4) Kestur, U. S.; Taylor, L. S. Cryst. Growth Des. 2013, 13, 4349-4354.

(5) Salvalaglio, M.; Vetter, T.; Giberti, F.; Mazzotti, M.; Parrinello, M.J. Am. Chem. Soc. 2012, 134, 17221-17233.

(6) Trasi, N. S.; Taylor, L. S. Cryst. Growth Des. 2012, 12, 3221-3230.

(7) Dowling, R.; Davey, R. J.; Curtis, R. A.; Han, G.; Poornachary, S. K.; Chow, P. S.; Tan, R. B. H. Chem. Commun. 2010, 46, 5924-5926.

(8) Clydesdale, G.; Roberts, K. J.; Docherty, R. J. Cryst. Growth 1994, 135, 331-340.

(9) Garnier, S.; Petit, S.; Coquerel, G. J. Cryst. Growth 2002, 234, 207219.

(10) Saleemi, A. N.; Onyemelukwe, I. I.; Nagy, Z. K. Front. Chem. Sci. Eng. 2013, 7 (1), 79-87.

(11) Agnew, L. R.; Cruickshank, D. L.; McGlone, T.; Wilson, C. C. Chem. Commun. 2016, 52, 7368-7371.

(12) Simone, E.; Steele, G.; Nagy, Z. K. CrystEngComm 2015, 17, 9370-9379.

(13) Vetter, T.; Mazzotti, M.; Brozio, J. Cryst. Growth Des. 2011, 11, 3813-3821.

(14) Ilevbare, G. A.; Liu, H.; Edgar, K. J.; Taylor, L. S. Cryst. Growth Des. 2012, 12, 6050-6060.

(15) Tian, F.; Baldursdottir, S.; Rantanen, J. Mol. Pharmaceutics 2009, 6 (1), 202-210

(16) Wu, Z.; Yang, S.; Wu, W. CrystEngComm 2016, 18, 2222-2238.

(17) Abu Bakar, M. R.; Nagy, Z. K.; Saleemi, A. N.; Rielly, C. D. Cryst. Growth Des. 2009, 9, 1378-1384.

(18) Saleemi, A. N.; Rielly, C. D.; Nagy, Z. K. CrystEngComm 2012, 14 2196-2203.

(19) Abu Bakar, M. R.; Nagy, Z. K.; Rielly, C. D. Cryst. Growth Des. 2010, 10, 3892-3900.

(20) Saleemi, A. N.; Steele, G.; Pedge, N. I.; Freeman, A.; Nagy, Z. K. Int. J. Pharm. 2012, 430, 56-64.

(21) Kim, J. W.; Kim, J. K.; Kim, H. S.; Koo, K. K. Org. Process Res. Dev. 2011, 15, 602-609.

(22) Yang, Y.; Song, L.; Nagy, Z. K. Cryst. Growth Des. 2015, 15 (12), 5839-5848.

(23) Powell, K. A.; Saleemi, A. N.; Rielly, C. D.; Nagy, Z. K. Chem. Eng. Process. 2015, 97, 195-212.

(24) Koswara, A.; Nagy, Z. K. IFAC-PapersOnLine 2015, 48 (8), $193-$ 198.

(25) Majumder, A.; Nagy, Z. K. AIChE J. 2013, 59 (12), 4582-4594.

(26) Snyder, R. C.; Doherty, M. F. AIChE J. 2007, 53 (5), 1337-1348.

(27) Snyder, R. C.; Veesler, S.; Doherty, M. F. Cryst. Growth Des. 2008, 8 (4), 1100-1101.

(28) Gadewar, S. B.; Hofmann, H. M.; Doherty, M. F. Cryst. Growth Des. 2004, 4 (1), 109-112.

(29) Lovette, M. A.; Muratore, M.; Doherty, M. F. AIChE J. 2012, 58 (5), 1465-1474.

(30) Jiang, M.; Zhu, X.; Molaro, M. C.; Rasche, M. L.; Zhang, H.; Chadwick, K.; Raimondo, D. M.; Kim, K. K.; Zhou, L.; Zhu, Z.; Wong, M.; O'Grady, D.; Hebrault, D.; Tedesco, J.; Braatz, R. D. Ind. Eng. Chem. Res. 2014, 53, 5325-5336.

(31) Eisenschmidt, H.; Voigt, A.; Sundmacher, K. Cryst. Growth Des. 2015, 15 (1), 219-227.

(32) Eisenschmidt, H.; Bajcinca, N.; Sundmacher, K. Cryst. Growth Des. 2016, 16 (6), 3297-3306.

(33) Qiu, Y.; Rasmuson, Å.C. AIChE J. 1990, 36 (5), 665-676.

(34) Rieck, G. D. Recl. Trav. Chim. Pays-Bas 1944, 63 (9), 170-180.

(35) van der Voort, E. J. Cryst. Growth 1991, 110 (4), 662-668.

(36) Docherty, R.; Roberts, K. J. J. Cryst. Growth 1988, 88 (2), 159168.

(37) Lemmer, S.; Ruether, F. Chem. Eng. Sci. 2012, 77, 143-149.

(38) Klapwijk, A. R.; Simone, E.; Nagy, Z. K.; Wilson, C. C. Cryst. Growth Des. 2016, 16 (8), 4349-4359.

(39) Simone, E.; Zhang, W.; Nagy, Z. K. Cryst. Growth Des. 2015, 15 (6), 2908-2919. 
(40) Kacker, R.; Salvador, P. M.; Sturm, G. S. J.; Stefanidis, G. D.; Lakerveld, R; Nagy, Z. K.; Kramer, H. J. M. Cryst. Growth Des. 2016, 16 (1), 440-446.

(41) Macrae, C. F.; Bruno, I. J.; Chisholm, J. A.; Edgington, P. R.; McCabe, P.; Pidcock, E.; Rodriguez-Monge, L.; Taylor, R.; Van De Streek, J.; Wood, P. A. J. Appl. Crystallogr. 2008, 41, 466-470.

(42) Iggland, M.; Mazzotti, M. Cryst. Growth Des. 2012, 12 (3), 14891500.

(43) Vetter, T.; Iggland, M.; Ochsenbein, D. R.; Hänseler, F. S.; Mazzotti, M. Cryst. Growth Des. 2013, 13 (11), 4890-4905.

(44) Baldan, A. J. Mater. Sci. 2002, 37, 2379-2405.

(45) Borsos, Á.; Majumder, A.; Nagy, Z. K. Cryst. Growth Des. 2016, 16 (2), 555-568.

(46) Borsos, Á.; Majumder, A.; Nagy, Z. K. Comput.-Aided Chem. Eng. 2014, 33, 781-786. 